\title{
Reviving or interring global governance on sustainability? Sachs, the UN and the SDGs
}

\author{
George Martine*
}

SACHS, J. D. The age of sustainable development. New York:

Columbia University Press, January 2015. 544 p.

\section{Planetary boundaries, Sachs and the UN}

The science is out and undisputable: Humankind is heading rapidly towards ecological disaster on several fronts, the most visible of which is climate change (STEFFEN, 2015; McNUTT, 2015; BARNOSKY, 2012). Radical measures are urgently needed to alter this trajectory yet they are not forthcoming. Getting a majority of governments to act effectively on these issues has repeatedly proved impossible. The latest multilateral initiative to deal with impending environmental catastrophes is the 2015 UN Sustainable Development Summit, an event that culminates a negotiating process spanning more than two years. The agenda? The approval of 17 "Sustainable Development Goals" (SDGs) that will succeed the 15-year tenure of the Millennium Development Goals (MDGs) at the forefront of UN operations. Both of these UN enterprises owe much of their intellectual inspiration to the work of Jeffrey Sachs. Ban Ki Moon identifies Sachs as his special advisor in the Foreword to The Age of Sustainable Development and many of the book's ideas are easily recognized in the SDG's formulations. In brief, it is an important and influential book that needs to be reviewed and discussed in some detail.

The acclaims received by Sachs for The Age of Sustainable Development are numerous and compelling. Inter alia, Lord Stern states that the book "explains clearly where we can go and how to get there"; Rajenda Pachauri finds that the book "is clear on what we need to make sustainable development a reality"; Harvard biologist Edward O. Wilson sees this book as "the most important in circulation". The nature and amount of praise for Sachs'

*Independent consultant, Brasília-DF, Brazil (georgermartine@yahoo.com). 
book, plus the fact that its ideas are reflected in the SDGs would appear to signal the dawn of a new era, one in which humankind is finally going to find a way out of the ecological mess it has created. Can we bank on it? My take is that we might need to take a longer look at Sachs' fundamental message and its ideological underpinnings before committing all our hopes to it.

\section{Scope, analytical framework and ideology}

Without a doubt, The age of sustainable development constitutes a tremendous tour de force in the encyclopaedist mode. It provides a cogent and eminently readable treatment of varied topics that are related in some way to sustainable development in 500 plus pages. Sachs' analysis ranges over economics, development and history and delves into such topics as health, education, gender issues, food supply, poverty, overpopulation, urbanization and social mobility, while also discussing authoritatively the origins and scale of species extinction, over-extraction from oceans, climate change and biological diversity. While the linkages between topics is not always evident, several of the individual chapters are so well researched and admirably presented that they can serve as self-standing references.

Despite this breadth of useful information, I would argue that the analytical framework of The Age of Sustainable Development is flawed and that, therefore, its basic message is dangerously misleading. Sachs generally describes the nature and gravity of the dangers created in the Anthropocene era accurately, but his proposed path to resolution is ultimately founded on the notion that we can essentially continue doing more of the same, only better. In a nutshell, his goal is to achieve "socially inclusive and environmentally sustainable economic growth". This objective needs to be carefully evaluated.

Since economic growth as we know it is the primary source of global environmental threats as well as of divisive inequality, Sachs' formulation immediately begs the question - how can this same growth become quickly inclusive and sustainable? The author's basic response is that this transformation can be accomplished through the promotion of an appropriate combination of better policies and improved technology, especially in the energy domain. Would that it were possible! Unfortunately, Sachs' analysis seriously underestimates the obstacles in the domain of political economy, while overrating the miracles to be operated by the markets and by technology. He also fails to perceive that economic growth, per se and into the foreseeable future, conflicts with atmospheric limits because the process involves continually-increasing consumption of dwindling resources.

\section{Policy, technology and consumption}

The critical environmental issues faced by humankind today are not new but have become more evident and acute in recent decades. Why has global governance been so inept at acting upon the analyses and recommendations that environmentalists have clamored 
for since Rio '92? In large part because those early warnings coincided with, and were superseded by, the global expansion of economic fundamentalism on the wings of free trade and deregulation policies imposed by international financial agencies.

Above and beyond the threat of economic sanctions to poor countries that did not conform to free trade precepts, the motor that drove the wildfire acceptance of this model was the rapid spread of the culture of consumption. Over the course of several decades since WW2, the culture of consumption had been carefully nurtured and successfully implemented in the United States and other richer countries, guaranteeing continuous increases in production and, thus, 'economic growth'. Globalization quickly spread this set of values and behavior patterns to the rest of the world and the desire to consume underlies global economic growth in today's 'civilization'.

The constellation of actors that support and implement this paradigm throughout the world is practically unassailable. Economic growth based on continuous increases in consumption has indeed been largely responsible for the outstanding reductions in global poverty, particularly in the last few decades. It has also assuaged the aspirations for increased consumption of billions (while leaving out more billions) over the same period. This process has been underwritten by the unsustainable use of non-renewable resources and the reduction of biodiversity while energy consumption from stored biomass has greatly increased carbon dioxide and methane emissions.

The fact that such economic growth is our only accepted path to poverty reduction and to the ever-greater consumption that we have all learned to desire has transformed it into the very raison d'être of governments and international development agencies. Not surprisingly, it finds its way into the well-meant proposals of multilateral organizations, such as in the SDGs. However, the fact remains that this paradigm stands directly in the path of attempts to mobilize governments towards effective agreements altering the current trajectory towards ecological chaos. Meanwhile, rich countries refuse to implement effective environmental measures for fear of indisposing their consumption-oriented electorates, as Sachs notes in the opposition of the United States to global environmental proposals. Poor countries, in turn, understandably aspire to growth that will reduce poverty and increase their populations' access to goods and products that are readily available in the rest of the world.

Given the institutional and political strength of economic growth based on constantly increasing consumption, where can we expect to find the political will to focus the economy on poverty reduction and sustainability? The power elite that shapes global economic policy is strongly influenced exactly by those agents that are in denial of climate change and planetary boundaries. Free trade has, in fact, meant the adoption of an economic structure based on fossil fuels and the encroachment of biodiversity. Under the logic of indiscriminate economic growth, multinational companies roam the world in search of greater profit, less taxes and lack of environmental controls. Part of the ideology of market fundamentalism involves exactly the reduction of the public sector, despite the fact that 
fossil fuel companies receive billions in subsidies, while the companies that have rocked global financial security were rewarded with massive government handouts. As Sachs himself observes - "Multinational companies are often the agents of public corruption, bribing officials to bend regulations or tax policies in their favor and engaging in tax evasion, money laundering and reckless environmental damage." This has created a smattering of super-rich people, destabilized financial markets and increased inequality within and between countries.

In short, dominant sectors of the market economy are at war with the environment and with social inclusion. It would seem rather irresponsible to trust this framework of economic organization to devise and implement policies and practices that will reverse the current environmental quandary.

If the policies that would alter the trajectory of economic growth from exclusive to inclusive and from unsustainable to sustainable are not likely to be forthcoming under the present configuration of the global political economy, can we expect technological breakthroughs to compensate increased consumption?

Whatever our vantage point, massive technological development, particularly in the energy sector, is clearly essential to remove the ecological Damocles sword currently hovering over the heads of humankind. Nevertheless, it would be foolhardy to believe that technology per se could overcome the damage already caused to the planet and counter the ill-effects of our headlong pursuit of economic growth. As noted earlier by Jevons and reiterated by many, including the eminent scientist and philosopher, Vaclav Smil, the rate of technological development, no matter how rapid, is never sufficient to cope with increased demand. The most urgent needs for technological breakthroughs are in the energy sector, which holds tremendous possibilities in terms of lowering emissions. Yet this is exactly the sector dominated by the most important environmental culprits and enemies of sustainability. Denial by the paid lackeys and lobbies of powerful corporations that stand to lose from a change in Business as Usual is a powerful factor opposing change. Sachs himself highlights the folly of banking on technological breakthroughs that will extend the fossil fuel industry through petroleum extraction from oil sands and hydrofracking. As he notes in this connection, "we are on the path of grave long-term planetary danger at the price of short-term market returns" (chapter 5).

In addition to the political obstacles to necessary technological development, fundamental technical problems are glossed over by Sachs. For instance, the literature relates tremendous problems involved in building vast energy grids, as well as in transporting renewable energy. Under the best of circumstances, it would take many years to build up a new system and a lot of fossil fuel would have to be burned to set it up. More generally, technological fixes present several clear limitations, as ably summarized by Tveberg (2014). A basic difference is that no source of energy will ever replace the cheap fossil fuels that made past development possible. Overall, however, the major problem stems from the fact that there are many resource limits besides fossil fuels and that almost 
every "solution" that we come up with simply transfers our problems from one area to another if we insist on continuing consumption.

To be fair, Sachs is not a complete techno-fix, nor even a firm believer in the miracle of the markets. Nevertheless, his whole approach is dominated by the hope that minor shifts in the capitalist system will be sufficient to arrest and revert the environmental threats he ably describes throughout his book. In today's globalized world, every country is trying to get a bigger bite in the global economic pie and very few are willing to give up anything for the sake of sustainability. The culture of consumption has been firmly ingrained as the engine that effectively stimulates further growth while satisfying the populace. Economic growth is the undisputed magical formula that both developed and developing countries adopt in the pursuit of happiness, enrichment and poverty reduction. The fact that it conflicts directly with atmospheric limits is, for the most part, explicitly ignored. Rich countries fully intend to maintain their privileges and their politicians will do anything - including the obstruction of multilateral environmental initiatives and the initiation of bellicose activities to guarantee "our way of life". Poor countries prioritize the improvement of their economic and social conditions through economic growth; they obviously will not retreat in their efforts if developed countries, who created the problem in the first place, fail to act.

\section{Over-population, over-development or bad development?}

Throughout this book, Sachs repeatedly refers to population size and growth as a primary obstacle to sustainable development. One would have to be blind to completely negate the importance of demographic dynamics in the environmental equation. However, Sachs' constant use of "per capita" and "per person average" in discussing sustainability reiterates some very common and unfortunate errors that surround the population issue. Given the difficulties of reversing the problems caused by our consumer civilization, anodyne solutions that would not oblige us to alter our development paradigm or our chosen 'way of life' are usually favored. Reducing population growth through family planning programs is probably the most widespread quick-fix policy espoused by decision-makers and the public-at-large. Although couching his recommendations in the politically-correct language of much needed improvements in reproductive health, Sachs sometimes wanders along the same misleading path.

There are several reasons to be wary of the population control panacea. First of all, it is based on an erroneous perception of the problem's roots. Our environmental quandary stems from increased consumption, not increased population. One unit of population (a "person") is not equivalent to one unit of consumption (a "consumer")! Actually, despite the rapid escalation of consumption in recent decades, two-thirds of the world's population still does not participate in global consumption and a quarter is frankly 'poor'. Given the recent concern with increasing environmental degradation in China and other emerging economies, it is easy to forget that the current ecological quandary was generated by a 
minority - the low-fertility population in industrial countries and the elites of other countries. The population of poor and high fertility countries only contributes to grave global ecological problems when it "develops" under the current paradigm.

Second, the relation between fertility decline and consumption is ambiguous. On the one hand, a reduction in fertility is associated at least as much with improving living conditions as it is with the availability of family planning programs. People reduce their fertility when there are concrete socio-economic motivations to do so, and such changes are normally associated with much-needed increases in 'consumption'. Urbanization is a major structural factor, both in providing people with the motivation and the tools to plan their fertility and in improving people's lives by giving them - on average - greater access to goods and services. This provides a good illustration of the fact that the immediate impact of a reduction in the denominator of the consumption equation tends to be countered by an increase in per capita consumption. It also draws attention to another critically important facet of population dynamics for both development and environmental outcomes that is usually neglected - urbanization.

Thirdly, the impact of fertility decline on global environmental problems is of the longerterm variety. Population inertia - which makes the number of current births dependent on the size of the female cohort born during the previous generation as much as on the present fertility rate - means that declining fertility does not have an immediate impact on population size. For this reason, reducing fertility NOW is very important for sustainability in future generations, but will not resolve the current predicament caused by the infringement of planetary boundaries by this and previous generations of consumers.

Fourth, the disturbing bottom line is that even if population growth rates were suddenly reduced and world population quickly stabilized in accordance with the lowest projections available, there still would not be room at the global consumer table for a substantial proportion of this contingent under current conditions.

The most urgent challenge of the current generation is how to improve the lives of the world's majority that is still poor without creating a state shift and extrapolating planetary boundaries beyond redemption. Currently, it seems that the only way we know how to 'develop' is to incorporate people into the consumer market by using ever-larger quantities of nature's resources. Since we are already overstepping Nature's boundaries by more than $50 \%,{ }^{1}$ the prospect of tripling the number of consumers, even with somewhat better policies and technology, is extremely worrisome. Better than any other argument, it illustrates the futility of trying to fix the Planet's serious ailments with Band-Aids and aspirins. As argued by prize-winning scientists in the Blue Planet - "There is an urgent need to break the link between production and consumption on the one hand and environmental destruction on the other". ${ }^{2}$

\footnotetext{
${ }_{1}^{1}$ Global Footprint Network, 2014 (http://www.footprintnetwork.org/en/index.php/GFN/).

${ }^{2}$ Available at: 〈http://pt.scribd.com/doc/82268857/Blue-Planet-Synthesis-Paper-for-UNEP〉.
} 


\section{Global governance and the SDGs}

The 1990s marked a high point in the history of the United Nations as it staged a sequence of seven multilateral conferences to debate critical social issues facing humankind during the détente. Meanwhile, however, the real destiny of the world economy was being radically transformed behind closed doors and those decisions ended up deflating the brave social proposals and recommendations of the UN Conferences. The MDGs emerged, under Sachs' inspiration, as a stopgap proposal to fill this void. The UN convinced participating governments that progress would now depend on setting up specific goals and targets in the social domain and on measuring changes in each of these over a 15-year period. Focusing the attention of multilateral organizations and national development agencies on these indicators effectively defused discussion of more weighty matters related to the global political economy, or to the environmental and social bumps in the road that appeared during this period.

Some notable advances were made that can be attributed to the framework of the MDGs, particularly in the health area, but the results are less clear in more complex areas of development. Although Sachs attributes the recent declines in poverty and the improvements on other indicators to this initiative, the impact of the MDGs is likely to be considerably inferior to that wrought by a favorable moment in the global economy, which was itself due largely due to a miracle economic period in China. It is interesting that, given a second chance to influence global policy, Sachs now turns exactly to economic growth as the engine and centerpiece of his proposal. However, the chances of success under the SDGs are considerably lower than they were for the less ambitious MDGs. The world is facing serious and mounting problems in economic growth, social well-being and environmental sustainability. A NASA-funded study warns that "global industrial civilisation could collapse in coming decades due to unsustainable resource exploitation and increasingly unequal wealth distribution". ${ }^{3}$ In this light, several critical topics - such as de-growth, throughput growth, entropy, consumerism, Piketty, military spending, Davos, the Arab Spring, fundamentalism, etc. - that are absolutely crucial to the present debate on planetary boundaries and social inclusiveness are glaringly absent from Sachs' encyclopedia.

Viewed in this context, the 2015 UN Sustainable Development Summit is, at best, an inadequate and equivocal approach to the resolution of humankind's major problems. At worse, the SDGs are deflecting attention from much more knotty problems of global governance. Signposts and roadmaps, as Sachs argues, can be useful in attaining certain measurable goals. However, the topics that need discussion are much more complex than the selection of adequate indicators to gauge some questionable progress on limited matters. Under the SDG format, countries and international organizations will again be put

\footnotetext{
3 The Guardian, 14 March 2014. Available at: 〈http://www.theguardian.com/environment/earth-insight/2014/mar/14/ nasa-civilisation-irreversible-collapse-study-scientists〉.
} 
to work defining and gathering data on a greater or smaller number of partial indicators while critical issues in the world's political economy will continue to be ignored. Reliance on continued economic growth as the pathway to sustainability and inclusion underlies this effort, ensuring that we will further encroach on planetary boundaries in the near future. If such critical issues of global governance are not seriously debated in a United Nations context, where can the discussion take place?

\section{References}

STEFFEN, W. et al. Planetary boundaries: guiding human development on a changing planet. Science, v. 347, n. 6223, January 2015.

MCNUTT, M. The beyond-two-degree inferno. 2015. Available at: 〈www.sciencemag.org〉. Access on: July 3, 2015.

BARNOSKY, A. D. et al. Approaching a state shift in Earth's biosphere. Nature, v. 486, p. 52-58, June 2012.

TVERBERG, G. Eight pitfalls in evaluating green energy solutions. Our Finite World. November 18, 2014. Available at: 〈http://ourfiniteworld.com/2014/11/18/eight-pitfalls-in-evaluating-greenenergy-solutions/>. Access on: July 3, 2015.

\section{About the author}

George Martine is a sociologist/demographer with a Ph.D from Brown University and M.A. from Fordham University. He is a former President of the Brazilian Population Association, Senior Fellow at the Harvard Center for Population and Development, Director of UNFPA's Technical Team for Latin America and the Caribbean and Director of the Institute for Society, Population and Nature, inter alia. He currently works as a consultant on issues of social development, population and environment.

\section{Contact address}

George Martine

SHIS QI 19/6/20

71655-060 - Brasília-DF, Brazil

Received for publication in $02 / 09 / 2015$

Recommended for publication in 07/09/2015

Accepted for publication in $05 / 10 / 2015$ 